\section{Chemical Repellents and Plastic Netting for Reducing Bird Damage to Sweet Cherries, Blueberries, and Grapes}

\author{
Paul D. Curtis \\ Department of Natural Resources, Cornell University, Ithaca, NY 14853
}

\author{
Ian A. Merwin, Marvin P. Pritts, and David V. Peterson \\ Department of Fruit and Vegetable Science, Cornell University, Ithaca, \\ NY 14853
}

Additional index words. Prunus avium, Vitis vinifera $\mathrm{x}$ labrusca, Vaccinium corymbosum, methyl anthranilate, methiocarb, bird-feeding deterrents, avian frugivory

\begin{abstract}
We conducted 3 years of field tests comparing two chemicals [methyl anthranilate (MA, a natural compound used as a flavor additive) and Keyplex-350 (a proprietary micronutrient formulation)] that were reported to repel birds to exclusionary plastic netting and nontreated plots. Cumulative fruit damage from birds was monitored on sweet and tart cherry (Prunus avium L. and P. cerasus L.), blueberry (Vaccinium corymbosum L.), and wine grapes (Vitis vinifera $x$ labrusca). Initial MA formulations caused injury to fruit and foliage. Two modified MA formulations with microencapsulation and photooxidation inhibitors provided significant reductions in bird damage and fruit splitting on sweet cherries in one of four experiments. A taste panel could not detect MA residues on sweet cherries at harvest. Bird damage was slightly reduced in MA-treated grapes, but damage to blueberries was similar in MA and control treatments. Keyplex did not deter birds from feeding on fruit and caused blemishes on and an unpleasant flavor in treated fruit. Many bird species were observed feeding on these fruit crops during successive years at the three experimental sites. Although these two chemicals have the potential to deter bird depredation, our work suggests that neither is consistently effective against all the frugivorous species in the northeastern United States. Chemical name used: 2-Aminobenzoic acid methyl ester [methyl anthranilate (MA)].
\end{abstract}

Damage to fruit crops by birds is a serious problem in fruit-producing areas throughout North America. Soft fruit such as sweet cherries, grapes, and blueberries are especially subject to bird depredation (Askham and Fellman, 1989). Avery et al. (1992) estimated that $10 \%$ of the U.S. blueberry crop was lost to birds in 1989 at a cost of $\$ 8.5$ million. A 1972 survey indicated that birds caused at least $\$ 4.4$ million in annual losses to the grape industry (Crase et al., 1976), and most of the growers responding to their survey thought that available bird control methods were ineffective. A more recent study indicated that grape losses to birds in the United States exceeded \$7

Received for publication 2 Dec. 1993. Accepted for publication 17 May 1994. Department of Fruit and Vegetable Science Paper no. 38. We thank P. Vog and L. Askham for developing and providing MA formulations, and D. Brunnetti for supplying micronutrient supplements for our experiments. M. Avery provided helpful advice during our field trials. T. Joseph, R. Tariche, P. Wellner, M. Moracco, and M.J. Kelly assisted with data collection and other field activities. W. Strack and J. Tamburello generously allowed us to conduct experiments in their blueberry farms. The cost of publishing this paper was defrayed in part by the payment of page charges. Under postal regulations, this paper therefore must be hereby marked advertisement solely to indicate this fact. million annually (Himelrick, 1985). Tobin et al. (1991) reported that major damage often occurred to early ripening cherries in the Hudson Valley, N.Y., although late-ripening cherries were less damaged by birds.

Until recently, ripening blueberries, grapes, and sweet cherries could be protected somewhat by treatment with 3,5-dimethyl-4(methylthio)phenol methyl carbamate (methiocarb) during the weeks before harvest (Tobin et al., 1989). However, the registration for methiocarb use on blueberries and cherries expired in 1986 (Tobin and Dolbeer, 1987), and there are no chemical repellents registered by the Environmental Protection Agency (EPA) for protecting fruit crops from birds. Plastic netting is another method that sometimes provides effective bird control, but it is prohibitively expensive for many fruit growers. Flying balloons resembling raptors, amcalls, periodic firing of propane cannons, placing rubber snakes in trellises, and other methods now are used with limited success by fruit growers eager for economic and effective bird control (Himelrick, 1985).

Recent research has focused on identifying and testing nontoxic, biodegradable chemicals that are aversive to problem birds but leave negligible residues on fruit. Certain polysaccharides have shown promise as repellents for a few bird species that have difficulty plified recordings of frugivorous birds distress digesting sucrose (Clark and Mason, 1993; Martinez del Rio, 1990). Brugger and Nelms (1991) documented that total food consumption by American robins (Turdus migratorius L.) was reduced when sucrose was added to their feed. Frugivorous birds such as starlings (Sturnus vulgaris L.) and robins apparently lack the digestive enzyme sucrase and can discriminate among fruit with mixed sugar types (e.g., fructose, glucose, and sucrose), avoiding those with more than $11 \%(\mathrm{w} / \mathrm{w})$ sucrose content (Brugger et al., 1993).

Another experimental approach for reducing bird depredation involves applying nontoxic sensory repellents, such as methyl anthranilate (MA) and related compounds (Clark and Shah, 1991). MA is a natural compound used as a flavor additive in the food industry (Vogt, 1992). MA is a constituent of many plants, including 'Concord' grapes (which are rarely damaged by birds) and orange [Citrus sinensis (L.) Osb.] blossoms (Bedoukian, 1967). It has been used as an additive in the food-flavoring and fragrance markets for many years and generally is regarded as safe by the U.S. Food and Drug Administration. In its pure form, MA is a volatile, oily substance that is phytotoxic; therefore, it must be reformulated to avoid leaf injury when applying to plants. Several manufacturers are reportedly pursuing EPA registration of microencapsulated MA formulations as a biorational bird repellent for nonfood uses near airports.

Recent laboratory (Mason et al., 1989) and field trials (Cummings et al., 1991; Dolbeer et al., 1992) have shown that MA is aversive to certain bird species. However, field tests with MA formulations that are appropriate for fruit crops have provided mixed results. Askham (1992) reported that MA applications reduced bird damage to sweet cherries and blueberries by $43 \%$ to $98 \%$ and $65 \%$ to $99 \%$, respectively, compared with nontreated controls. However, its efficacy in these tests varied among cultivars, foraging pressures, and crop loads. Avery (1992) evaluated two MA formulations in a 0.2-ha aviary enclosure containing highbush blueberries. Neither formulation protected blueberries from foraging by penned cedar waxwings (Bombycilla cedrorum Vieillot). In fact, MA-treated fruit sustained more bird damage than nontreated controls in Avery's field enclosure study, despite previous observations that MA was aversive to waxwings in laboratory cage trials.

Several New York fruit growers noted that they had observed reduced bird damage in cherry orchards where they had applied foliar sprays of a polysaccharide formulation containing essential plant nutrients (Keyplex-350; Morse Enterprises, Miami). During the summers of 1991 to 1993, we conducted field tests on stone fruit, grapes, and blueberries to evaluate MA and Keyplex compared to birdexcluding plastic nets and nontreated controls. Our objectives were to evaluate the effectiveness of MA and Keyplex compared to netting control strategies for birds feeding on cherries, grapes, and blueberries and to document the relative frequency of particular bird species observed feeding on these crops in New York. 


\section{Materials and Methods}

Formulations of repellents. The MA formulations used in our tests are described in Table 1. Bird Shield is a proprietary emulsion formulation of Washington State Univ. (WSU), Pullman. RejeX-iT was custom-manufactured for our tests by PMC Specialties Group, Cincinnati, in three successive formulations because field observations indicated that formulation changes were necessary to reduce phytotoxicity and increase field persistence of the active ingredient. The initial MA formulation (MA-1) that we used in 1991 was a wettable powder that was difficult to maintain in aqueous suspension. A subsequent formulation (MA-3) was microencapsulated to prevent leaf injury, and the last formulation (MA4) was microencapsulated and a proprietary photooxidation inhibitor was added to extend the residual effectiveness of the active ingredient on the fruit surface. The Bird Shield repellent (MA-2) also was a proprietary emulsion formulation including a photooxidation inhibitor. Keyplex-350 is a proprietary micronutrient formulation labeled for foliar applications in fruit and vegetable crops; it contains the following nutrient elemental concentrations (percent, w/w): $4.0 \mathrm{~S}, 1.5 \mathrm{Mg}, 0.75 \mathrm{Mn}$, $3.5 \mathrm{Fe}, 0.75 \mathrm{Zn}, 0.006 \mathrm{Cu}, 0.16 \mathrm{~B}$, and 0.003 $\mathrm{Mo}$, formulated as salts of sodium glucoheptanates and alpha ketonic acids in a polysaccharide base. We applied Keyplex at the manufacturer's recommended rate of 2 liters/ 390 liters of water $(0.05 \% \mathrm{v} / \mathrm{v})$ per hectare. We used a motor-powered, backpack, mist-blower sprayer to apply all of the repellents, spraying until first visible leaf runoff. Water spray was not applied as a control treatment in any of the tests.

\section{Field trial limitations}

The relatively small size of fruit plantings in New York places significant limitations on the scale of experiment designs. Although our treatment units consisted of several trees or bushes and nontreated buffer trees or bushes were included between replications in every test, it was not possible to separate repellenttreated plots by more than a few meters. Furthermore, because all treated fruit had to be discarded and our tests occurred in commercial fruit plantings, economic limitations restricted the treated plot size. Therefore, we recognize that border effects from nearby treatments may have impinged on our control plots.

\section{Cherries}

Sweet and sour cherries, 1991. Preliminary experiments with 20-year-old 'Napolean' sweet cherry and 'Montmorency' tart cherry trees were conducted during Summer 1991 at the Cornell Research Farm, Lansing, N.Y. This small planting consists of 1.5 ha of sweet and tart cherries, surrounded on three sides by a mixed hardwood forest and on the fourth side by apple trees. Bird immigration, therefore, was relatively uniform throughout the cherry orchard used in these tests. Trees were sprayed to runoff with aqueous suspensions of MA-1 at $2 \%$ a.i. (w/w) and Keyplex at $0.5 \%(\mathrm{v} / \mathrm{v})$ weekly during the 3 weeks before harvest. Due to the difficulties of maintaining this formulation in a uniform suspension, MA-1 distribution was not uniform on the leaf surface, and phytotoxicity was severe on foliage and fruit of both crops. Moreover, bird depredations were negligible and not significantly different among treatments; therefore, these data are not presented. Following these tests, the manufacturer reformulated the MA to improve its mixture stability and minimize phytotoxicity.

Sweet cherries, 1992. The next year, treatments were applied to 'Hartland' sweet cherry trees at the Lansing orchard. Plastic netting, MA-3, Keyplex, and nontreated control plots were randomized in four blocks of four-tree plots in adjacent rows. Buffer trees were situated at the end of each row and between treated trees to lessen edge effects. Chemicals were applied to runoff on 22 and 29 June, at $1.2 \%$ a.i. (v/v) for MA-3 and $0.5 \%$ (v/v) for Keyplex, with a commercial spreader-activator (Triton AG; Rohm and Haas Co., Philadelphia) added to both treatments. Netting was draped over trees on 22 June and removed at harvest on 6 July 1992. On a planting of 'Napolean' sweet cherries elsewhere in the same orchard, we conducted a nonreplicated test of another proprietary MA formulation (MA-2) developed at WSU (Table 1), according to the protocol of an Interregional Research Project (IR-4) dealing with residue analysis (no. 5026.92-NY24). Plots of 18 trees were sprayed to runoff with two concentrations ( 1.1 and $2.2 \mathrm{~kg}$ a.i./ha), and fruit losses were recorded from 22 June through 6 July 1992.

To evaluate bird damage to fruit, three branches with $\approx 30$ fruit per branch were selected in $120^{\circ}$ sectors around each tree at 1.2 to $1.8 \mathrm{~m}$ above ground and tagged on 15 June for subsequent damage counts. Fruit on tagged branches was subsequently classified into one of three categories (undamaged, partially eaten or marked, and missing) and counted at 3- to 4day intervals until harvest. Data were recorded as cumulative percent fruit damage or loss (Askham and Fellman, 1989).

To assess which bird species were causing fruit damage, we conducted observational counts at 3- to 4-day intervals during the first $2 \mathrm{~h}$ after sunrise from two sites providing good visibility at end of tree rows. The number and species of all birds entering the test site from each edge of the orchard were recorded.

Sweet cherries, 1993. Another field test was conducted at the same 'Hartland' sweet cherry orchard to compare three new MA concentrations $[1.2 \%, 2.4 \%$, and $4.8 \%$ a.i $(\mathrm{v} / \mathrm{v})$ sprayed to runoff] with photooxidation inhibitors (MA-4, Table 1). The design was similar to the previous year's - a randomized block with four replications of each MA concentration and a nontreated control. A single treatment application was made on 18 June, and fruit was monitored until harvest on 1 July 1993. Because of wet weather preceding harvest, the incidence of rain-induced fruit splitting was also recorded in this test. A total of 80 to 100 fruit were randomly selected from three to four branches on each tree during counts on 1 July, and the average proportion of split fruit was determined. All other methods were identical to those described for the 1992 tests.

We conducted a simple taste test to determine whether people could detect MA residues on fruit at harvest. Sweet cherries were randomly sampled from control and treated trees in 1993. The fruit was immediately placed in plastic bags, tagged, and put in a cooler with ice. Within $2 \mathrm{~h}$ postharvest, the fruit was rinsed with cool tap water, and a taste trial was conducted with 24 volunteers to determine if they could detect MA-4 residues on treated cherries. Three cups, each containing three fruit, were placed in front of each volunteer. Two cups contained fruit from nontreated trees, and one cup contained fruit treated with MA at various concentrations. Volunteers were told that one cup contained MA-treated fruit and were asked to select that cup and mark its number on a data form.

\section{Blueberries}

Two field trials with 'Bluecrop' were conducted during Summer 1992. At the Tamburello Farm, Trumansburg, N.Y., MA-2 was evaluated in two concentrations $(1.5 \mathrm{~kg}$ a.i./90 liters of water and $2.6 \mathrm{~kg}$ a.i./170 liters of water, both per hectare) and compared to nontreated controls. Treatments were applied 22 and 29 July and 5 Aug. in 6-m plots arranged in a completely randomized design with four replications. Bird depredation was not evaluated, but undamaged fruit from each plot were harvested on 12 Aug. and weighed. In a test at the Strack Farm, Tioga County, N.Y., 16 plots consisting of nine bushes each and spanning three rows were established in an L-shaped configuration at a corner of the blueberry field that had sustained the most bird damage during preliminary tests in 1991; this placement ensured consistently high bird pres-

Table 1. Chemical ingredients, brand names, and formulations evaluated as bird repellents for sweet cherries, blueberries, and grapes during field tests in New York.

\begin{tabular}{llll}
\hline \hline $\begin{array}{l}\text { Abbrevi- } \\
\text { ation }\end{array}$ & \multicolumn{1}{c}{ Active ingredient and formulation } & \multicolumn{1}{c}{$\begin{array}{l}\text { Brand } \\
\text { name }\end{array}$} & \\
\hline MA-1 & Methyl anthranilate 45\% a.i. (w/w) slurry & ReJeX-iT & PMC Specialties Group, 501 Murray Rd., Cincinnati, OH 45217 \\
MA-2 & Proprietary starch encapsulation & Bird Shield & Washington State Univ., Pullman, WA 99164 \\
MA-3 & $21.8 \%$ a.i (w/w) microencapsulated & ReJeX-iT & PMC Specialties Group \\
MA-4 & $14.5 \%$ a.i. (w/w) microencapsulated, plus antioxidants & ReJeX-iT & PMC Specialties Group \\
Keyplex & alpha-ketonic acids proprietary formulation & KeyPlex 350 & Morse Enterprises, 151 S.E. 15 Rd., Miami, FL 33129 \\
\hline
\end{tabular}


sure across all replications. Four replications of MA-3, Keyplex, plastic netting, and nontreated controls were assigned in a randomized block design. Aqueous mixtures of MA$3(1.2 \%$ a.i. v/v) and Keyplex $(0.5 \%$ v/v) were applied to runoff on 13, 20, and 27 July and 4 and 10 Aug. 1992, as previously described. Netting was draped over frameworks consisting of aluminum pipe and wire on 13 July.

Bird damage was evaluated at the Strack Farm only in the center bush of each plot, to lessen edge effects. Six branches with $\approx 20$ to 40 unripe fruit per branch were selected and tagged on the center bush in each plot for subsequent damage counts. Tagged branches were evaluated at 3- to 4-day intervals from 13 July to 20 Aug. to determine fruit loss. On each sampling date, fruit was classified as undamaged, partially eaten or marked, or missing, and counted to determine cumulative percentage loss (Askham and Fellman, 1989). Birds were identified and counted at 3- to 4-day intervals as previously described.

\section{Grapes}

Field trials were conducted at the Prejean Vineyard, Yates County, N.Y., in a 6-ha vineyard containing several grape cultivars, including 'Maréchal Foch' - an early ripening red cultivar that had suffered severe bird damage at this site in previous years. Sixteen plots of five 'Maréchal Foch' vines each were selected near an overhead power line frequented by birds. Plots were arranged in a square configuration spanning four rows; two fruit clusters per vine were tagged for subsequent bird-damage counts. Three vines were left nontreated between plots to minimize the effects of spray drift. Four replications of Keyplex, MA-4, netting, and control treatments were assigned to plots in a randomized block design. Aqueous mixtures of MA-4 ( $1.2 \%$ a.i. v/v) and Keyplex ( $0.5 \%$ v/v) were applied to runoff on 2 and 11 Sept. 1992; netting was draped over the trellis supports for appropriate plots on 2 Sept.

Grape clusters were selected based on the uniformity of fruit load $(\approx 80$ to 100 fruit per bunch). Tagged clusters were examined at 3 to 4-day intervals from 2 to 18 Sept. to determine fruit loss. Berries in each cluster were classified as undamaged, partially eaten or marked, or missing; because it was difficult to obtain exact counts within large clusters, losses from tagged clusters were subsequently estimated to the nearest percent. Bird counts were conducted on 11,15 , and 18 Sept., as described for previous experiments.

\section{Statistical analyses}

The mean proportion of undamaged fruit was calculated for each treatment at each sampling date. Standard analysis of variance models were used, as appropriate, to test for significant differences between treatments, and Fisher's protected LSDS or pairwise contrasts were used to separate arcsin square-root-transformed treatment means.

\section{Results}

Sweet cherries. During 1992, fruit damage was extensive in all treatments in the 'Hartland' planting, including the netting treatment in which foraging raccoons displaced several nets. There were no significant differences among treatments on any preharvest sampling date, and at harvest, there was less damaged fruit in the netting treatment (Fig. 1). Similarly, no differences in fruit damage were observed between the two concentrations of MA-2 formulation on 'Napolean' cherries in the same orchard (Fig. 2). Bird pressure was heavy in the orchard throughout these studies (Table 2). Various bird species were responsible for cherry losses, including American goldfinches (Carduelis tristis L.), house finches (Carpodacus mexicanus Muller), sparrows (Spizella, Melospiza, and Zonotrichia spp.), cardinals (Cardinalis cardinalis L.), robins, and gray catbirds (Dumetella carolinensis L.). No flocks of European starlings were observed in this block during the trial, although individual starlings were observed foraging in the trees.

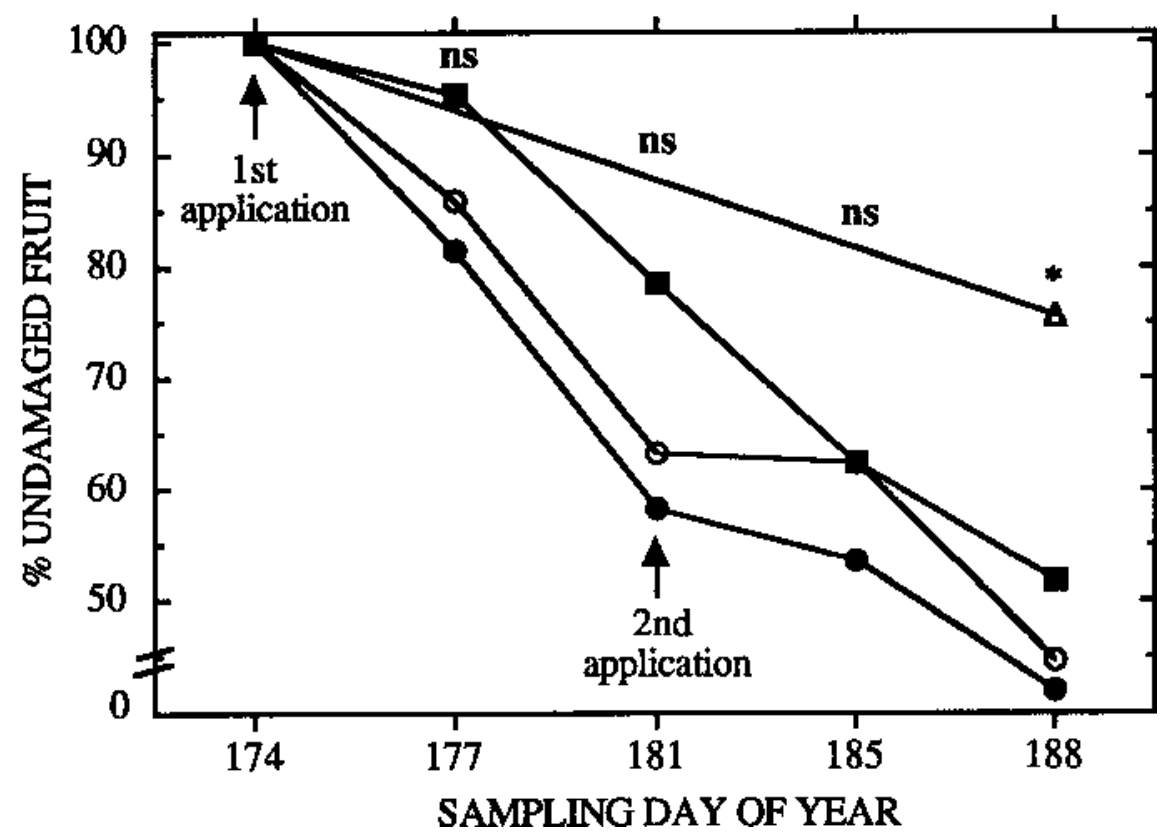

Fig. 1. Percent undamaged 'Hartland' sweet cherries in three bird repellent treatments and control plots at the Lansing Research Farm near Ithaca, N.Y., sampled from 22 June (day of year, 174) to 6 July 1992. Values are means of four replications. (O) MA-1 (2\% w/w), (ם) Keyplex $(0.5 \% \mathrm{v} / \mathrm{v}),(\Delta)$ netting, and $(\bullet)$ nontreated control. There were fewer damaged $(P \leq 0.05)$ fruit on netted trees at harvest (day 188).

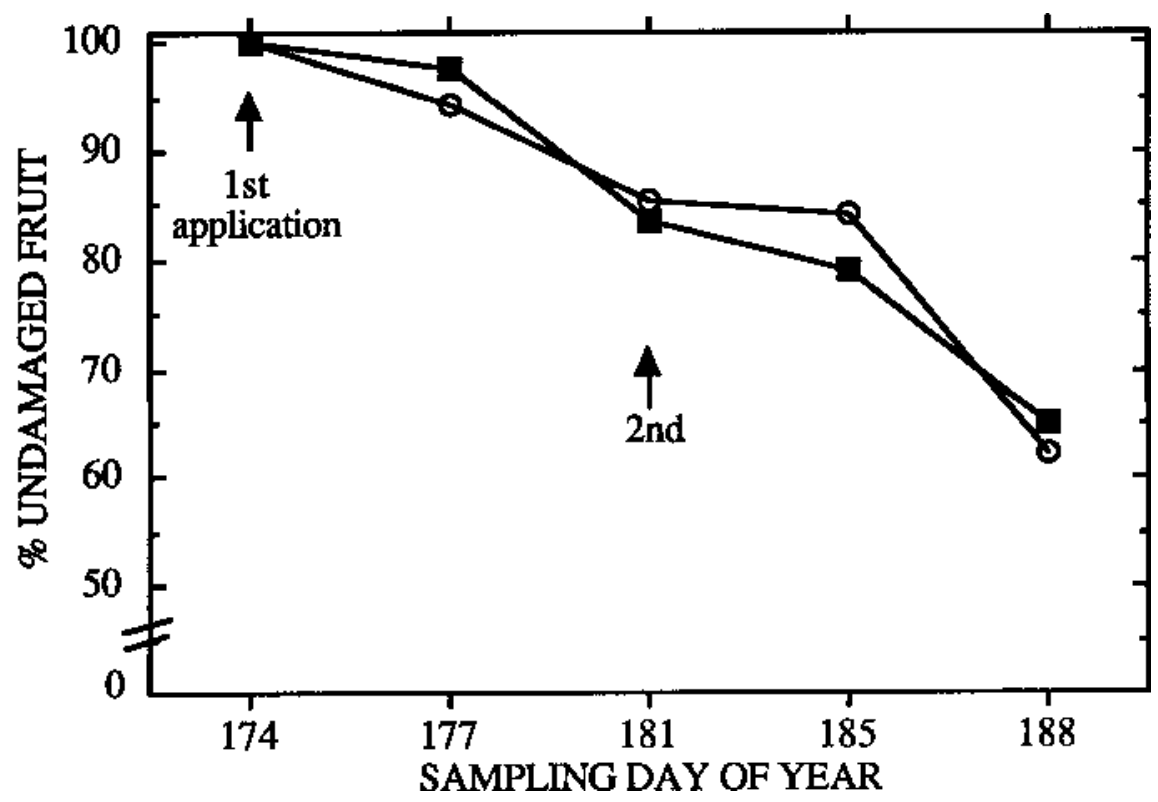

Fig. 2. Percent undamaged 'Rainier' cherries in plots sprayed with MA-2 at (O) 1.1 and (匚) $2.2 \mathrm{~kg}$ a.i./ha, at the Lansing Research Farm near Ithaca, N.Y., 22 June (day of year, 174) to 6 July 1992. Values are means of 10 sampled trees for each nonreplicated MA concentration. None of the treatment differences were significant. 
Pest Management

Table 2. Bird species observed feeding on various fruit crop plots in New York during Summer 1992 and 1993. Values are total successive counts observed at dawn during the preharvest period and the percentage of total birds represented by each species. ${ }^{2}$

\begin{tabular}{|c|c|c|c|c|c|c|c|c|c|c|c|c|c|c|c|c|c|c|}
\hline \multirow[b]{3}{*}{ Fruit crop } & \multicolumn{16}{|c|}{ Bird species } & & \\
\hline & \multicolumn{2}{|c|}{$\begin{array}{l}\text { House } \\
\text { finch }\end{array}$} & \multicolumn{2}{|c|}{$\begin{array}{c}\text { Amer. } \\
\text { robin }\end{array}$} & \multicolumn{2}{|c|}{$\begin{array}{c}\text { Amer. } \\
\text { goldfinch }\end{array}$} & \multicolumn{2}{|c|}{ Sparrow } & \multicolumn{2}{|c|}{ Cardinal } & \multicolumn{2}{|c|}{$\begin{array}{c}\text { Cedar } \\
\text { waxwing }\end{array}$} & \multicolumn{2}{|c|}{$\begin{array}{c}\text { Gray } \\
\text { catbird }\end{array}$} & \multicolumn{2}{|c|}{$\begin{array}{l}\text { Mocking- } \\
\text { bird }\end{array}$} & \multicolumn{2}{|c|}{$\begin{array}{c}\text { European } \\
\text { starling }\end{array}$} \\
\hline & No. & $\%$ & No. & $\%$ & No. & $\%$ & No. & $\%$ & No. & $\%$ & No. & $\%$ & No. & $\%$ & No. & $\%$ & No. & $\%$ \\
\hline \multicolumn{19}{|l|}{ Cherries } \\
\hline Hartland 1992 & 52 & 27.1 & 49 & 25.5 & 44 & 22.9 & 21 & 10.9 & 11 & 5.7 & 0 & 0 & 4 & 2.1 & 1 & 0.5 & 3 & 1.6 \\
\hline Napolean 1992 & 2 & 2.3 & 26 & 29.9 & 8 & 9.2 & 11 & 12.6 & 2 & 2.3 & 8 & 9.2 & 21 & 24.1 & 1 & 1.2 & 0 & 0 \\
\hline Hartland 1993 & 55 & 43.0 & 16 & 12.5 & 1 & 0.8 & 22 & 17.9 & 4 & 3.1 & 0 & 0 & 11 & 8.6 & 7 & 5.5 & 8 & 6.3 \\
\hline Napolean 1993 & 22 & 33.9 & 5 & 7.7 & 5 & 7.7 & 7 & 10.8 & 2 & 3.1 & 0 & 0 & 3 & 4.6 & 2 & 3.1 & 7 & 10.8 \\
\hline Blueberries & 22 & $3.5^{\mathrm{y}}$ & 37 & 5.9 & --- & --- & 63 & 10.0 & 0 & 0 & 52 & 8.2 & 0 & 0 & 0 & 0 & 341 & 54.0 \\
\hline Grapes & 26 & 3.9 & 0 & 0 & --- & --- & 12 & 1.8 & 0 & 0 & 0 & 0 & 0 & 0 & 0 & 0 & 557 & 83.3 \\
\hline
\end{tabular}

${ }^{2}$ This list includes the primary fruit-eating species observed during morning counts. Other birds observed in the plots (i.e., swallows, eastern bluebirds, flycatchers, morning doves, etc.) that were primarily insect- or seed-eating species are not included.

yThese percentages include a few American goldfinches that were not separated for analyses.

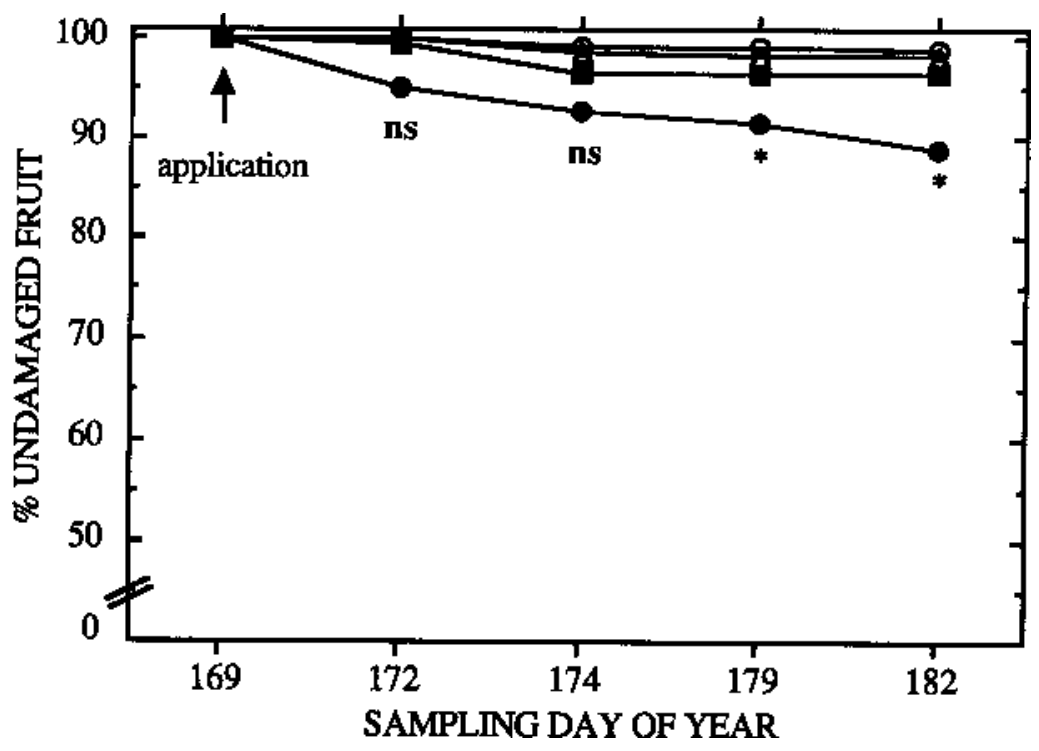

Fig. 3. Percent undamaged 'Hartland' sweet cherries in plots sprayed with MA-4 at three concentrations (percent, w/w): $1.2(\bigcirc), 2.4(\mathbf{\square}), 4.8(\Delta)$, and nontreated controls $(\bullet)$ at Lansing Research Farm near Ithaca, N.Y., 18 June (day of year, 169) to 1 July 1993 . Values are means of four replications. MA-4 treatment means as a group were significantly $(P \leq 0.05)$ less damaged than the control treatments on day 179 , and at harvest on day 182 .

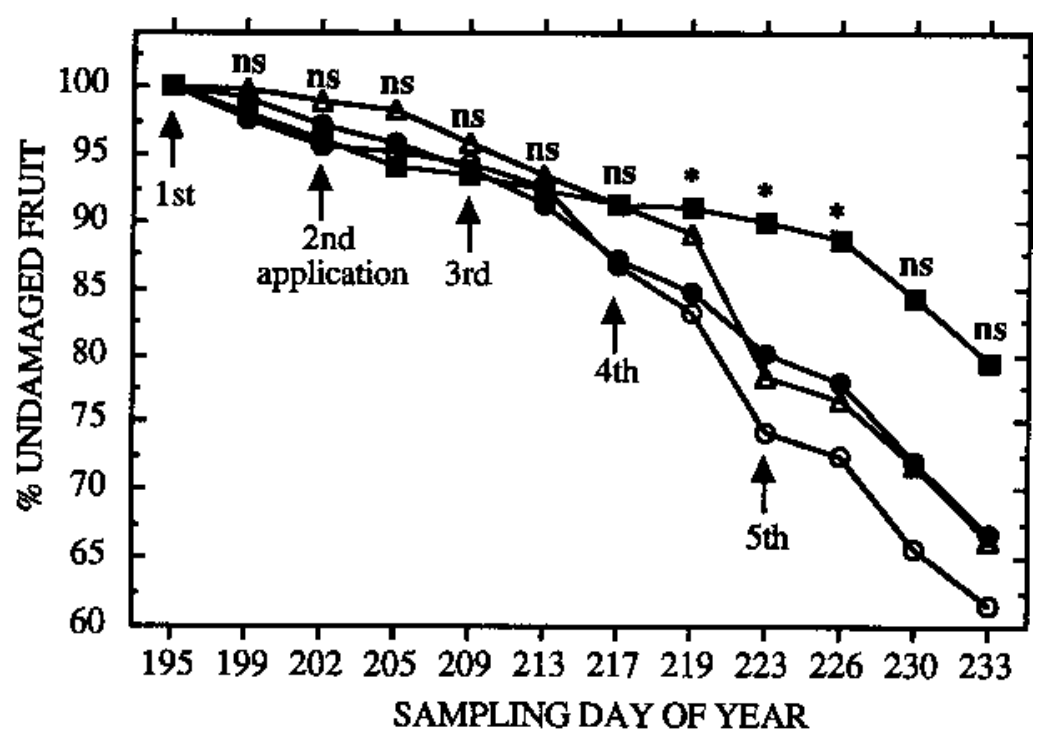

Fig. 4. Percent undamaged 'Bluecrop' blueberries at Strack Farm, Tioga County, N.Y., sampled 13 July (day of year, 195) to 20 Aug. 1992. Values are means of four replications. (O) MA-3 (1.2\% w/w), ( $\Delta$ ) Keyplex $(0.5 \% \mathrm{v} / \mathrm{v}),(\square)$ netting, and $(-)$ nontreated controls. On days 219,223 , and 226 , fewer fruit were damaged $(P \leq 0.05)$ in netted than in MA-treated plots.
During 1993, 'Hartland' cherry trees sprayed with any of the three MA-4 concentrations received less bird damage than control plots on day 179 and at harvest on day 182 (Fig. 3). The effects of different MA-4 concentrations were equivalent. Also, cherries sprayed with MA-4 exhibited significantly less splitting than nontreated fruit at harvest (mean split fruit was $18 \%$ vs. $48 \%, P \leq 0.001$ ).

In our taste panel evaluations for MA residues, four of the $24(17 \%)$ volunteer panelists could detect no difference between the three sample cups provided. Seven of the remaining 20 panelists $(35 \%)$ correctly selected the cup that contained MA-treated fruit, and 13 volunteers $(65 \%)$ incorrectly identified a cup with nontreated fruit. These results were not significantly different from random chance $\left(\chi^{2}\right.$ test), indicating that MA-4 residues were not consistently detectable in this trial. For the seven cups with MA-treated fruit that were correctly identified, one was from the lowest, and three each were from the two higher concentration treatments.

Blueberries. In our tests on 'Bluecrop' blueberries at the Tamburello Farm, there was some evidence of bird repellency in MA-2 treatments. Mean plot yields varied with MA2 concentration rates $(3.7,3.8$, and $4.8 \mathrm{~kg}$ fruit per plot and $0,1.5$, and $2.6 \mathrm{~kg}$ a.i./ha, respectively), but this trend was not statistically significant. At the Strack Farm blueberry planting of the same cultivar, $\geq 10 \%$ of the blueberries were damaged in all plots after the first four treatment applications (days 195 to 217), and there were no significant differences among any treatments (Fig. 4). Bird foraging pressure subsequently increased as flocks of starlings began frequenting the site on day 223 (Table 2 and Fig. 4). One week after the fourth and fifth applications (days 219 to 226), there was less damage in netted plots than in the MA-3 treatments.

Grapes. Berry damage was negligible in all vineyard treatments in 1992 . Fewer than $2 \%$ of tagged fruit were damaged by birds in any treatment, and there were no significant differences among Keyplex, MA-3, and control treatments except at harvest, when there was slightly more damage $(P \leq 0.05)$ in the nontreated clusters. European starlings, mourning doves (Zenaida macroura L.), finches, and sparrows were the primary species observed in the vineyard, but starlings were most com- 
mon and presumably accounted for most of the minimal damage (Table 2).

\section{Discussion}

In the absence of effective chemical controls for bird depredation on soft fruit, there is considerable interest among growers in compounds such as MA and Keyplex. There are anecdotal reports that some growers are already experimenting independently with orchard and vineyard applications of commonly available carbonated beverages artificially flavored with sucrose and MA. Chemical manufacturers are also applying for MA formulation registrations as bird repellents (Cummings et al., 1991), and IR-4 funds have been allocated for MA-residue testing on sweet cherries. For these reasons, we believe that rigorous testing of MA efficacy under field conditions is essential, and we have compiled this report despite the generally negative results of our multiyear field tests involving multiple formulations of purported avian repellents on three fruit crops. Injury to fruit and foliage following applications of certain MA formulations confirm that there is potential crop risk involved in using some MA formulations (Avery, 1992). Furthermore, we observed significant reductions in bird depredation on MAtreated fruit in only one of six field trials (Fig. 3 ). In one of our tests (Fig. 4), there was actually more bird damage in MA-treated than in control plots, as also reported by Avery (1992). However, in our most recent tests with sweet cherry, we did observe significant reductions of bird depredation without detectable residues or blemishing of cherries, and the possible further benefit of reduced fruit splitting after preharvest rains using an MA formulation that was microencapsulated and protected against photodecomposition. Because fruit splitting and losses to birds are major problems in sweet cherry production, these results could entail substantial yield increases for cherry growers if they are confirmed in subsequent tests.

The failure of MA to reduce bird damage during our 1991 and 1992 tests may have resulted from rapid photodecomposition of the active ingredient in its earlier formulations. Askham (1992) documented that MA degraded rapidly after 8-h exposure to incandescent, fluorescent, or ultraviolet light and that $<1 \%$ of the initial MA remained in exposed test samples after $64 \mathrm{~h}$ of light exposure. We also noted that, despite the lack of significant differences in fruit damage at individual sampling dates in our 1992 field tests, there did appear to be a 3-day reduction in bird depredation indicated by a transitory leveling off of the cumulative damage slope (Figs. 1 and 2) fol- lowing several MA applications. Another factor that may complicate interpretation of MA field tests is the volatility of the active ingredient. The characteristic cloying odor of this compound was noticeable to us at a considerable distance $(\geq 25 \mathrm{~m})$ from treated trees. If birds are equally sensitive to MA, it is possible that the repellent effect of the compound might extend considerably beyond the treated fruit or trees. This effect might reduce bird depredation in nearby nontreated as well as treated plots, making it difficult to provide valid controls in orchard tests. In this context, it is worth noting that, in several of our MA tests on cherries in 1991 and on grapes in 1993, there was unusually little bird damage throughout the plantings compared with previous years at these sites.

Although caged bird feeding tests of Keyplex-350 by K. Brugger (unpublished) demonstrated some aversion to fruit by starlings, our field tests showed little benefit from this compound. As previously noted, these observations may have been biased by wafting volatiles from adjacent MA plots. Another problem involved fruit residues of this micronutrient formulation. After two spray applications, the material either covered or removed the waxy bloom usually observed on blueberries and grapes, and fruit that we tasted in the field had a noticeably bitter flavor. Consequently, fruit treated close to harvest with Keyplex may not be marketable.

Various bird species frequented the fruit plantings in our studies, and the observed damage usually could not be attributed to any single species (Table 2), although large flocks of juvenile starlings began to frequent blueberry fields during the first week of August, when fruit losses in the blueberry plots increased dramatically. These observations suggest that growers using avian distress calls for bird control should use a variety of speciesspecific recordings, because the control of only one or a few bird species may not adequately protect the crop. Although MA and polysaccharides have the potential to deter feeding by birds, considerably more work is needed to identify nonphytotoxic formulations with adequate, but not excessive, persistence on the fruit surface and that are effective against the various avian species causing serious damage to fruit crops.

\section{Literature Cited}

Askham, L.R. 1992. Efficacy of methyl anthranilate as a bird repellent on cherries, blueberries and grapes. Proc. 15th Vertebrate Pest Conf., Univ. of California, Davis 15:137-141.

Askham, L.R. and J.K. Fellman. 1989. The use of DMA to reduce robin depredation on cherries. Proc. Great Plains Wildlife Damage Control Conf. 9:116-119.
Avery, M.L., J.W. Nelson, and M.A. Cone. 1992. Survey of bird damage to blueberries in North America. Proc. Eastern Wildlife Damage Control Conf. 5:105-110.

Bedoukian, P.Z. 1967. The anthranilates, p. 41-46. In: Perfumery and flavoring synthetics. Elsevier Publishing Co., New York.

Brugger, K.E. and C.O. Nelms. 1991. Sucrose avoidance by American robins (Turdus migratorius): Implications for control of bird damage in fruit crops. Crop Protection 10:455-460.

Brugger, K.E., P. Nol, and C.I. Phillips. 1993. Sucrose repellency to European starlings: Will high-sucrose cultivars deter bird damage to fruit? Ecol. Appl. 3:256-261.

Clark, L. and J.R. Mason. 1993. Interaction between sensory and postingestional repellents in starlings: Methyl anthranilate and sucrose. Ecol. Appl. 3:262-270.

Clark, L. and P.S. Shah. 1991. Nonlethal bird repellents: In search of a general model relating repellency and chemical structure. J. Wildlife Mgt. 55:538-545.

Cornell Univ. Agricultural Expt. Station. 1984. Blackbirds and starlings in agricultural pest situations-Regional research project NE-102 Progress Report: Population dynamics, habitat utilization, and foraging strategies of roosting blackbirds. Dept. Natural Resources, Cornell Univ., Ithaca, N.Y.

Crase, F.T., C.P. Stone, R.W. DeHaven, and D.F Mott. 1976. Bird damage to grapes in the United States with emphasis on California. U.S. Dept. Interior, Fish and Wildlife Serv. Spec. Sci. Rpt. 197.

Cummings, J.L., J.R. Mason, D.L. Otis, and J.F. Heisterberg. 1991. Evaluation of dimethyl and methyl anthranilate as a Canada goose repellent on grass. Wildlife Soc. Bul. 19:184-190.

Dolbeer, R.A., L. Clark, P.P. Woronecki, and T.W Seamans. 1992. Pen tests of methyl anthranilate as a bird repellent in water. Proc. Eastern Wildlife Damage Control Conf. 5:112-116.

Himelrick, D. 1985. Battling the birds: The war without mesurol. Eastern Grape Grower and Winery News August/September:22-25.

Martinez del Rio, C. 1990. Dietary, phylogenetic, and ecological correlates of intestinal sucrase and maltase activity in birds. Physiol. Zool. 63:987-1011.

Mason, J.R., M.A. Adams, and L. Clark. 1989 Anthranilate repellency to starlings: Chemical correlates and sensory perception. J. Wildlife Mgt. 53:55-64.

Tobin, M.E. and R.A. Dolbeer. 1987. Status of mesurol as a bird repellent for cherries and other fruit crops. Proc. Eastern Wildlife Damage Control Conf. 3:149-158.

Tobin, M.E., R.A. Dolbeer, and C.M. Webster. 1989. Alternate-row treatment with the repellent methiocarb to protect cherry orchards from birds. Crop Protection 8:461-465.

Tobin, M.E., R.A. Dolbeer, C.M. Webster, and T.W. Seamans. 1991. Cultivar differences in bird damage to cherries. Wildlife Soc. Bul. 19:190-194.

Vogt, P.F. 1992. ReJeX-iT ${ }^{\mathrm{TM}}$ brand bird aversion agents. Proc. 15th Vertebrate Pest Conf., Univ. of California, Davis 15:134-136. 